\section{Eating in place: Mapping alternative food procurement in Canadian Indigenous communities}

\author{
Special JAFSCD Issue \\ Indigenous Food Sovereignty in North America \\ sponsored by
}

\section{Swette Center for Sustainable Food Systems} Arizona State University

\author{
Jennifer Sumner ${ }^{a *}$ and M. Derya Tarhan ${ }^{b}$ \\ University of Toronto
}

J. J. McMurtry ${ }^{c}$
York University

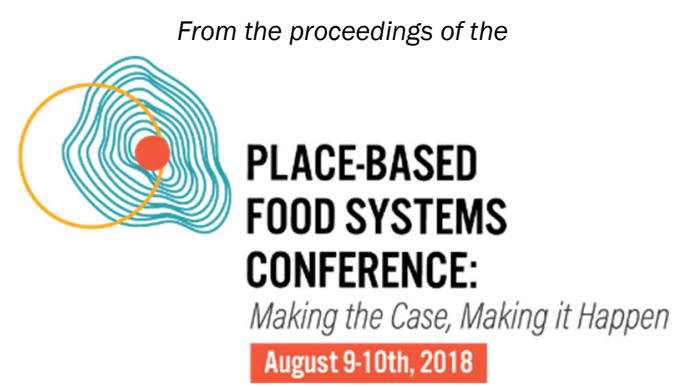

Submitted December 11, 2018 / Revised March 14, April 29, and July 24, 2019 /

Accepted July 25, 2019 / Published online December 17, 2019

Citation: Sumner, J., Tarhan, M. D., \& McMurtry, J. J. (2019). Eating in place: Mapping alternative

food procurement in Canadian Indigenous communities. Journal of Agriculture, Food Systems, and

Community Development, 9(Suppl. 2), 239-250. https://doi.org/10.5304/jafscd.2019.09B.016

Copyright (C) 2019 by the Authors. Published by the Lyson Center for Civic Agriculture and Food Systems. Open access under CC-BY license.

\begin{abstract}
This paper reports on alternative food procurement initiatives in Canadian Indigenous communities. Like many communities around the world, they have experienced the 'nutrition transition' toward nutritionally compromised industrial food, with debilitating results. Much of this change in
\end{abstract}

a * Corresponding author: Jennifer Sumner, Lecturer, Adult Education and Community Development Program, Ontario Institute for Studies in Education, University of Toronto; 252 Bloor Street West; Toronto, Ontario M5S 1V6 Canada; jennifer.sumner@,utoronto.ca

b PhD Candidate, Adult Education and Community Development Program, Ontario Institute for Studies in Education, University of Toronto; 252 Bloor Street West; Toronto, Ontario M5S 1V6 Canada; md.tarhan@mail.utoronto.ca

c Dean, Liberal Arts and Professional Studies, York University; South Ross 900, 4700 Keele Street; Toronto, Ontario M3J 1P3 Canada; imcmurtr@yorku.ca nutritional status has been created by a lethal combination of self-serving government policy and predatory corporate practice that ghettoizes Indigenous communities within a for-profit pseudo-food system. To find solutions to the colonially structured food deserts imposed on them, many Indigenous communities have turned to the social economy, initiating projects such as community gardens, greenhouses, and co-operatives. While largely unrecognized in the wider world, these initiatives are created and managed by communities, for the benefit of communities, giving us a deeper understanding of what place-based food systems can accomplish.

\section{Keywords}

Colonially Structured Food Deserts, Food Procurement, Indigenous Communities, Nutrition Transition, Place-Based Food Systems, Social Economy 


\section{Introduction}

Place-based food systems involve an interdependent web of activities that include the production, processing, distribution, consumption, and disposal of food in a particular place (Sumner, 2017).

Around the world, these systems carry the potential not only to address the needs of communities, but also to support their development. In Canada, Indigenous communities developed place-based food systems, anchored in traditional foods harvested locally (also known as country food). These traditional food systems include all the food within a particular culture that is available from local natural resources and is culturally accepted, while at the same time encompassing socio-cultural meanings, acquisition and processing techniques, use, composition, and nutritional consequences for the peoples using these foods (Kuhnlein \& Receveur, 1996). However, the ongoing forces of colonization have degraded or destroyed these traditional systems and compromised Indigenous people's access to the land and resources that underwrite their ability to continue eating in place. The result is what is known as food deserts - areas where nutritious and affordable food is not readily available (Koç, Sumner, \& Winson, 2017).

Much has rightly been made about the intractable issues facing Indigenous people (Truth and Reconciliation Commission of Canada [TRC], 2015), including the challenges of eating in place. However, media, academic, and popular attention has largely remained on developing a general and often paternalistic awareness of these problems rather than focusing on existing solutions. This is particularly true in terms of food procurement. The astronomical cost of fresh and nutritious food and the negative results of the 'nutrition transition' to lower-cost industrial food in many Indigenous communities have been identified in some quarters, but the collective place-based solutions community residents have devised to overcome these challenges largely have been overlooked.

This paper focuses on alternative food procurement in Canadian Indigenous communities through the lens of a "just transition," which aims to reduce social inequality (Heffron \& McCauley, 2018). The paper will begin by discussing just transition and its logical obverse, unjust transition, illustrated by the social economy and the nutrition transition. It will then outline the present research's approach to mapping sites of alternative food procurement and report on research findings. It will conclude by discussing how Indigenous communities are building Indigenous food sovereignty and food security through food procurement initiatives and the role these initiatives play in the just transition from colonially structured food deserts to a place-based food system.

\section{Just Transition}

The concept of a just transition proposes that justice and equity must be integral parts of any transition toward a low-carbon world (United Nations Research Institute for Social Development [UNRISD], 2018). Developed in the 1980s by the U.S. trade union movement as a response to new regulations to reduce air and water pollution by shutting down offending industries (Newell \& Mulvaney, 2013), a just transition can be broadly understood as "a vision-led, unifying and placebased set of principles, processes and practices that build economic and political power to shift from an extractive economy to a regenerative economy" (Climate Justice Alliance [CJA], n.d., p. 1). While the term 'transition' has gained credence as a result of the increasing recognition of the need to move to a lower-carbon future (e.g., Transition Towns), there is no guarantee that such a transition will be fair and equitable. A just transition addresses this issue by drawing attention to the quality of the transition itself, emphasizing that if the process of transition is not just, the outcome will never be (CJA, n.d.). In this situation, justice involves both social justice - the assignment of rights and responsibilities within society (Sumner, 2005)—and environmental justice - the well-being and rights of past and future generations, equity considerations based in race, class, gender, and nation, and our rights and obligations toward nonhuman forms of nature (Pulido, 2000). As the charter of the Global Greens (2001) states, "there is no social justice without environmental justice, and no environmental justice without social justice" ("Social Justice," para. 2). From an Indigenous perspective, Corntassel (2012) lays the groundwork for such a just transition when he links social and environmental 
justice to a resurgence of traditional foods (including community roles and responsibilities to protect traditional lands and food systems) as necessary acts of resurgence and pathways toward reconciliation, all of which will help to restore sustainable relationships with the land, culture, and communities.

In their book Just Transitions: Explorations of Sustainability in an Unfair World, Swilling and Annecke (2012) argue that a just transition needs to be based on a mode of production that does not depend on either resource depletion or environmental degradation, and needs to address widening inequalities regarding consumption and access to power. They propose that there is no single transition pathway that is relevant for all contexts, but add that such a transition requires deep structural changes, emphasizing issues such as the importance of food security and the requirement for both alternative diets and agro-ecological farming practices to restore the soil.

While the concept of just transition has generally been applied to energy, it can apply equally well to food and the necessity of the transition to sustainable, less energy-intensive food systems (see, for example, Heffron \& McCauley, 2018). In this vein, Gilbert, Schindel, and Robert (2018) use school food as "an entry point for introducing a just transition to the local food system, enhancing food equity built from healthier social, economic, ecological, and political systems" (p. 95). They maintain that a just transition is holistic in scope and encompasses five crucial activities that interact and overlap: democratize engagement, decentralize decision-making, diversify economic activity, decrease consumption, and (re)distribute resources and power. Following Gilbert et al. (2018), we argue that Indigenous food initiatives also can be an entry point for introducing a just transition to the local-place-based-food system, which would increase food security, support the environment, and enhance sustainability.

In light of the recognition that such a transition is inevitable, but justice is not (CJA, n.d.), it is important to acknowledge the obverse of just transition: unjust transition. Some transitions clearly have not been just and have benefited a privileged few. In essence, an unjust transition is informed by “ecological modernization ... via large-scale, topdown techno-fixes, co-managed by powerful corporate elites with access to new global funding mechanisms" (Swilling \& Annecke, 2012, p. 181). One example is what is known as the nutrition transition.

\section{An Unjust Transition: The Nutrition Transition}

The nutrition transition refers to a change in a population's nutrition status, which is characterized by increasing rates of obesity, cardiovascular disease, and various cancers (Koç, Sumner, \& Winson, 2012). The term was developed by Popkin (2003), who observed dietary changes moving into the developing world and subsequently increased rates of noncommunicable diseases. These dietary changes, often referred to as the 'Western diet,' were associated with exceptional consumption of saturated fats, sugar, salt, and refined foods. After noting the 'Western diseases' that invariably follow the introduction of the Western diet, Pollan (2008) points out that although humans have adapted to many types of diets, the Western diet is not one of them. This is especially true for Indigenous communities, as we will discuss below.

Samson (2016) observes that the nutrition transition is the most important issue affecting the health of Indigenous peoples around the world. Describing it as "a change from gathered, farmed, fished, and hunted foods to industrialized energydense diets" (p. 1), he adds that the nutrition transition has been accompanied by shifts in the population from being physically active to being sedentary. In their discussion of what constitutes good food, Martin and Amos (2017) investigate the nutrition transition taking place in Canada's Indigenous communities and the heavy burden of chronic disease associated with the transition, pointing to the impact of colonization on the way the nutrition transition has manifested in these communities and the chronic food insecurity experienced by many Indigenous people. When analyzing the food crisis in Indigenous communities, these authors stress the traditional importance of food in the realization of community among Indigenous cultures, and argue that respecting traditional cultural practices in terms of food must constitute part of the solution to colonization and industriali- 
zation needed in many Indigenous communities, and indeed in other communities and cultures around the globe.

For many remote communities in Canadian sub-Arctic regions, the Northern Store (owned and operated by the Hudson Bay Company until 1987) has been the conduit for the nutrition transition because both the cost and quality of the foods it purveys do not support healthy dietary choices (Thompson, Kamal, Alam, \& Wiebe, 2012). In more southern communities, supermarkets, convenience stores, and fast-food outlets spark the nutrition transition through their offerings of pseudo foods- "nutrient-poor edible products that are typically high in fat, sugar, and salt and, other than the calories they provide, often in overabundance, are notably low in nutrients such as proteins, minerals, and vitamins essential for health" (Winson, 2017, p. 187)—which are undermining healthy eating behaviors in society.

Nowhere has this undermining of healthy eating behaviors been more apparent than in Indigenous communities, which have been targets of genocidal government policy and predatory exploitation by for-profit corporations. As Martin (2012) argues, rather than being an inevitable by-product of development, the nutrition transition requires a more nuanced approach to assessment that "sheds light on how an individual's food 'choices' are often the product of government policies and marketing strategies that promote processed and refined foods to the exclusion of more traditional or unprocessed foods" (p. 208). Such an approach includes recognizing the creation and enforcement of what we refer to as colonially structured food deserts—-structurally imposed spaces that benefit narrow partisan political objectives and corporate profiteering through the purveyance of externally procured, culturally insensitive, pseudo foods to vulnerable communities.

Compounding this unjust transition, food has long been a weapon of government policy aimed at Indigenous people in Canada, from the establishment of the country to the present day. The first prime minister of Canada, John A. MacDonald, withheld the food promised in signed treaties to coerce Indigenous people onto reserves (Daschuk, 2015). And the scanty meals served to Indigenous children forced into the residential school system resulted in high levels malnutrition, sickness, and death throughout the $20^{\text {th }}$ century (TRC, 2015). Currently, the foods imported into northern Indigenous communities by the Northern Store are not culturally attuned, are often low-quality processed foods, and are significantly overpriced despite subsidies from government - creating high profits for corporations and negative economic and health impacts for communities and households. Government plans to address this problem, such as Nutrition North Canada, are seen as ineffective; "a 2014 Auditor-General's report ... raised doubts on whether subsidies given to retailers were being properly passed on to consumers" (Hui, 2016, para. 13). In addition, Canada's 2007 Food Guide for First Nations, Inuit and Métis recommends products such as fresh produce and meats, which are prohibitively expensive in remote communities (Burnett, Skinner, Hay, LeBlanc, Chambers, 2017), while the 2019 Canada's Food Guide does not yet directly address Indigenous people. In short, the predominant form of food procurement in Indigenous communities is creating colonially structured food deserts.

The unique problem resultant of these colonially structured food deserts, facilitated by collusion between the government and the private sector, is the ghettoizing of Indigenous communities within and by a for-profit pseudofood system. And this uniquely oppressive system is perpetuated by a difficult-to-penetrate myth of colonial paternalism-the idea that only the government or the private sector is able to solve the food problems of Indigenous communities. The colonial legacy of the Indian Act is therefore maintained through a policy of food system paternalism and reinforced through corporate complicity, continuing a long tradition of economic marginalization and cultural erasure. This returns us to the issue of what alternative form of food procurement is called for to reverse the unjust nutrition transition and encourage a just transition—one that respects traditional cultural practices, supports fairness and equity, and overcomes colonially structured food deserts. One path to a just transition can be found through the social economy. 


\section{A Just Transition: The Social Economy}

The origins of the social economy (or the third sector) date to long before the period of industrialization (or the modern state) (Shragge \& Fontan, 2000), but its importance is growing at a time when the state has either withdrawn from economic activity or has sided almost completely with private interests. In contrast to the neoliberal capitalist economy, the social economy aims to create an egalitarian, inclusive, and more deeply democratic society that promotes social justice and equality (Molloy et al., 1999, in Amin, Cameron, \& Hudson, 2002), making it a potential vehicle for a just transition. In essence, the social economy involves "economic activity neither controlled directly by the state nor by the profit logic of the market; activity that prioritizes the social well-being of communities and marginalized individuals over partisan political directives or individual gain" (McMurtry, 2010, p. 31). Co-operatives, nonprofits, credit unions, and mutual associations are some of the organizations that participate in the social economy, operating both within and against the neoliberal market (Sumner, 2017).

Faced with a wide range of negative consequences of neoliberalism, more and more people are turning to the social economy for solutions to their problems (see McMurtry, 2010; Mook, Quarter, \& Ryan, 2010). This is particularly true in the area of food, as evidenced by the proliferation of food co-ops, food hubs, food banks, and food programs. While some of these ventures might be effective, Goodman, Dupuis, and Goodman (2014) suggest that the social economy "is not up to the structural challenge of equalizing access to healthy food" (p. 83). Indeed, after discussing the market orientation of alternative food networks in general, Goodman et al. assert that the Achilles heel of these networks is social justice because "the poor and disadvantaged continue to be ill-served" (p. 84), which calls into question the efficacy of the social economy as a vehicle for a just transition. This reflects the work of Cook, Smith, and Utting (2012) in their United Nations occasional paper on a fair transition, in which they highlight the social economy as one of several just transition paths to a green economy. From Cook et al.,'s perspective, the positive social aspects of the social economy as a vehicle for a just transition include redistribution (in terms of income, wealth, and power), rights, social justice, equality of outcomes, empowerment, and citizen action. The positive environmental aspects involve environmental justice, agroecology, and grassroots action. The positive economic aspects encompass deglobalization, localization, institutional reform, and regional solidarity. However, these authors warn that the path is a contested one if inequalities are not addressed.

One area of the social economy that seems to counter such warnings and open up possibilities for a just transition involves Indigenous organizations, although Wuttunee (2010, p. 210) acknowledges that the Aboriginal community is grappling with the term 'social economy':

The presumption must be that the social economy label is a term that comes from outside a given community — and as such may or may not fit with the terminology used by that community for naming its experience, even though many aspects of what is labelled by the concept describes centuries-old Aboriginal practice.

For Wuttunee (2010), the social economy has emerged as an effective community development tool for two reasons: it allows for a variety of forms, and it maintains control in the hands of Aboriginal communities. She suggests that cooperatives, in particular, offer Indigenous communities a measure of autonomy over their development and allow for the realization of community values, with any profit being under community control. For these reasons, she points out that Aboriginal people are more likely than the general Canadian population to be members of cooperatives, and that co-ops have been especially well used by Aboriginal people as a way to meet community needs. This study builds on Wuttunee's work by mapping alternative, place-based food procurement in Canadian Indigenous communities. At the heart of these initiatives is the desire and the will to overcome the unjust nutrition transition caused by the colonially structured food deserts that characterize many Indigenous communities 
and to forge a just transition via the social economy to a more sustainable, place-based food system.

\section{Methodology}

We used a three-stage method to assemble a map and a corresponding Canada-wide database of alternative food procurement in Indigenous communities. The initial step in the research process was to conduct an online search using the keywords "Indigenous/First Nation/Inuit/Metis food project" and "Indigenous/First Nation/ Inuit/Metis food program." We used an online search engine to scan related media articles, information from support organizations (i.e., organizations that provide financial and/or logistical support) and reports, and conducted a search using the same keywords via ProQuest and Google Scholar for academic articles. As a result of this initial search, various types of Indigenous food initiatives were identified, including but not limited to such things as co-operatives, community gardens, community food markets, traditional food initiatives in healthcare institutions, and school gardens. Subsequently, a secondary online search (via both an online search engine and academic databases) was conducted for each type of initiative, resulting in the identification of numerous additional initiatives and organizations that implement or support alternative food procurement in and/or by Indigenous communities. The third stage of the online search involved an inquiry into the websites of, and grey literature (e.g., reports) published by, these support organizations to reveal additional Indigenous-led food procurement initiatives.

Throughout all three stages, we entered key initiative details (location, initiative type, leading organization, supporting organizations, related links, and a brief description of each initiative) into a database (Microsoft Excel). Subsequently, this Excel sheet was uploaded to Google MyMaps, free online software that transforms databases into geographic maps. On this map, each initiative is represented with a pin that is clickable for detailed information. ${ }^{1}$ The pins are color-coded according to three layers of initiative categorizations:

(1) Initiative type (e.g., Indigenous co-op, community garden, community market, etc.);

(2) The type of group or organization leading the initiative (e.g., Indigenous community, not-for-profit organization, school board, healthcare institution, etc.); and

(3) The type of group or organization playing a supporting role in the initiative (e.g., notfor-profit organization, Indigenous community, school board, healthcare organization, government agency, etc.).

These categorizations allowed for an inquiry into general and jurisdiction-specific trends pertaining to alternative food procurement in Canadian Indigenous communities, along with the identification of key actors and support mechanisms in the field. Findings based on this inquiry are presented and discussed in the following section of this paper. These findings are derived from publicly available material posted by Indigenous organizations themselves and offer a respectful scan of their social-economy initiatives.

\section{Findings and Discussion}

The three-stage research process identified 167 place-based Indigenous food procurement initiatives across Canada. The largest numbers by far of these social-economy initiatives were community gardens and greenhouses (58), followed by co-operatives (42), school gardens (17), food markets (9), community-based food programs (9), harvesting and hunting initiatives (5), education and training (5), institutional food (4), community kitchens (2), procurement initiatives (2), and single initiatives including but not limited to a food aid program, a food bank, a food distribution center, a combined food market-community garden-greenhouse, and a harvesting and a hunting initiative focused on food aid. Overall, the findings suggest several

1 The map of these initiatives can be found at https://www.google.com/maps/d/edit?mid=1oJUIKoPXI-_vVxB6kjEt$\underline{\mathrm{yW}} \mathrm{WV5} 6 \mathrm{Qmpu \& ll}=52.166426075353804 \% 2 \mathrm{C}-97.79301950000001 \& \mathrm{z}=3$ ) 
trends among these alternative food procurement initiatives.

\section{Place-based}

Very importantly, these initiatives are place-based and target local problems. These place-based initiatives have arisen in direct response to the placeless, faceless industrial food system at the heart of the unjust nutrition transition. This dysfunctional food system erases place and provenance and offers no opportunity for respectful relationships, depending instead on exploitative ones. In contrast, these Indigenous food procurement initiatives are rooted in place, meet the needs of local people (not corporate owners or shareholders), contribute to community development, and offer a glimpse of a place-based food system.

\section{Indigenous-led}

These initiatives are predominantly led by Indigenous communities and often are supported by other organizations. Across the country, initiatives are springing up that represent local leadership working to solve community food-related problems. The province of Manitoba is a prime example, as illustrated by the Northern Manitoba Food, Culture, and Community Collaborative

(NMFCCC), a not-for-profit organization made up of an interconnected group of people, communities, organizations, and governments, which provides financial and technical support to Indigenous-led food initiatives. In a recent report, the NMFCCC (2017) highlighted 20 projects and thanked the many allies and partners who supported them. Another example of leadership and support is the partnership between Indigenous communities and CHEP Good Food Inc., a notfor-profit organization working to improve access to good food and promote food security in Saskatchewan. Besides supporting Indigenous-led food initiatives through various programs, CHEP also has a Good Food Box Program that procures food directly from Flying Dust Cree8 Worker Cooperative and Muskoday Growers Co-operative.

\section{Gardens}

There has been a surge in the number of community and school gardens, some of which evolve into co-ops, such as the small community garden and food market in Flying Dust First Nation in Saskatchewan that eventually turned into a cooperative that produces food for the local community (and beyond) and employs numerous community members. We found 58 community and school gardens, many of which are promoted by the NMFCCC in Manitoba. These gardens help to overcome colonially structured food deserts by working to improve food access, establish knowledge of gardening and healthy living, encourage food sharing, promote healthy eating habits, support community members in starting their own gardens, and even "change the local food system to reduce dependency on southern food supplies" (NMFCCC, 2017, p. 31).

\section{Food Co-ops}

Many of these initiatives are food co-operatives. This corroborates Wuttunee's (2010) finding that co-ops have been especially well used by Aboriginal people as a way to meet community needs. Of the 167 alternative food procurement initiatives we identified, 42 were Indigenous co-ops, many being in the far north where food procurement can be challenging.

\section{Public Institutions}

Hospitals and universities are becoming involved with traditional foods. For example, the Yukon Hospital Traditional Diet Program offers patients access to traditional food and medicine (Yukon Hospitals, 2018). Kwantlen Polytechnic University (British Columbia) provides education and training at the Tsawwassen First Nation Farm School, and the University of Western Ontario and the University of British Columbia host Indigenous school and community gardens.

\section{Geographic Concentration}

Lastly, the findings reveal that certain initiative types show high levels of geographical concentration in Canada. This concentration can be linked to the existence of federations and not-for-profit agencies that support Indigenous food initiatives through procurement, financing, technical and educational support, and the provision of a platform for knowledge exchange and collaboration. A 
prime example is Arctic Co-operatives Limited, a co-op federation providing service and technical support to 32 Indigenous-owned and -controlled co-operative businesses located in Nunavut, the Northwest Territories, and the Yukon. These cooperatives provide a wide range of goods and services to the often remote and underserved Indigenous communities they serve, but food retail makes up the majority of their business activities (Arctic Co-operatives Limited, 2007). As a result, the map shows a very high concentration of Indigenous coops in these areas, where they are addressing food shortages and supporting community economic development. Another testimony to the importance of support organizations is the NMFCCC. Its support has enabled the proliferation of community gardens in the province of Manitoba, which has a much greater concentration of this initiative type compared with other provinces. These instances signal the significance of supportive organizations for individual Indigenous communities, which may lack the financial and technical resources to execute such initiatives. The broadening of co-operative relations between Indigenous communities and support organizations can accelerate the proliferation of Indigenous-led food procurement initiatives in Canada, especially by remote communities that are geographically and economically isolated.

Taken together, these findings bring into focus the role that place-based Indigenous alternative food procurement initiatives rooted in the social economy can play in overcoming the unjust nutrition transition and supporting a just transition to a place-based food system.

\section{Reversing the Unjust Nutrition Transition}

When calling for policies that encourage landbased activities as a means to mitigate the negative effects of adverse nutrition transitions, Samson (2016) notes that Indigenous foods and the exercise required to procure them are strongly associated with good physical and mental health. Testaments to this positive impact of place-based food initiatives can be found across Canada, but one specific case is worth mentioning here: Fox Lake Goose Camp, hosted by the Fox Lake Cree Nation in Northeastern Manitoba. For five days every spring, the children and youth from the community learn traditional goose hunting, preparation, and cooking methods from the elders in the community. The hunted meat is then shared among community members, who often lack access to highly nutritious local food options (Food Matters Manitoba, 2011). In addition, this initiative helps younger generations learn and retain traditional self-sustenance methods, which in turn strengthens their capacity to reverse the nutrition transition over the long term. The collective nature of procuring, preparing, and enjoying local goose meat has a significantly positive impact on the physical and mental health of community members, who are also able to preserve their culture and traditions through this multigenerational initiative.

\section{Supporting a Just Transition}

These place-based Indigenous food procurement initiatives can help to support a just transition to a place-based food system anchored in Indigenous food sovereignty and food security. While both are complex and contested terms, proponents of food sovereignty maintain that it is a precondition to genuine food security (McMichael, 2010; Patel, 2010).

\section{Indigenous food sovereignty}

While the concept of food sovereignty is fairly new, Morrison (2011) points out that the living reality of food sovereignty is not new for Indigenous communities; she goes on to argue that the "underlying principles of Indigenous food sovereignty are based on our responsibilities to uphold our distinct cultures and relationships to the land and food systems" (p. 97). Eschewing a strict definition, she maintains that the term describes the current strategies that both enable and support the capacity of Indigenous communities to sustain their traditional hunting, fishing, gathering, farming, and distribution practices. Crucially, she concludes, Indigenous food sovereignty provides "a framework for exploring, transforming and rebuilding the industrial food system towards a more just and ecological model for all” (p. 98). The place-based Indigenous alternative food procurement initiatives identified in this study 
align with Morrison's description of Indigenous food sovereignty by adhering to traditional methods of relating to land and food while furthering Indigenous self-determination through direct control of and benefit from such initiatives. One specific type of initiative that can play a critical role in establishing food sovereignty for Indigenous communities is community-based food programs, which focus on food and nutrition from a comprehensive perspective. Involved with various activities around food and nutrition, these programs intend to build local capacity for exercising and establishing food sovereignty. An exemplar of community-based food programs is the Ithinto Mechisowin ${ }^{2}$ Program (IMP) implemented by the O-Pipon-Na-Piwin Cree Nation $(\mathrm{OPCN})$ in Northern Manitoba. In collaboration with local actors such as the OPCN Band, the local school, and local fishers' and trappers' associations, IMP provides training to youth on wild food and medicine harvesting, preparation, preservation, and cooking techniques. The food that is harvested and prepared is then distributed to 400 local community members based on availability, need, and number of family members (NMFCCC, 2016). Adhering to the principles of food sovereignty, IMP is "managed by a community committee that includes elders, teachers, health care professionals, fishers, and more" (NMFCCC, 2016, p. 1). A number of community members reported weight loss, lower levels of blood sugar, and reduced hypertension, thanks to their now-regular intake of wild food. Furthermore, the program has been recognized by community members for boosting their mental health as it helped them reconnect with traditional foods and healthier nutrition (NMFCCC, 2016). The OPCN suffered immensely, in the early 1970s, by flooding from the hydroelectric dam commissioning and subsequent displacement of the community from their traditional lands. Pursuing food sovereignty through a community-led program championing traditional forms of food procurement and preparation has helped heal community members both physically and mentally (NMFCCC, 2016, p. 1).

2 Ithinto Mechisowin means "from the land" in Cree language.
Indigenous food security

These place-based Indigenous alternative food procurement initiatives can also help to achieve a just transition to a place-based food system that is anchored in food security. Unlike food sovereignty, which involves a rights-based approach to food, food security focuses on access to food. It has been defined as:

a condition that exists when all people at all times have physical, social, and economic access to food that is safe and consumed in sufficient quantity and quality to meet their dietary needs and food preferences, and is supported by an environment of adequate sanitation and health services and care, allowing for a healthy and active life. (Koç, Sumner, \& Winson, 2017, pp. 385-386)

The Centre for Studies in Food Security (2018) at Ryerson University promotes the five As of food security: availability, accessibility, adequacy, acceptability, and agency. This focus is reflected in the Indigenous food procurement initiatives this study identified, which are most often started by Indigenous communities themselves and therefore grounded in a local understanding of food-related barriers and solutions. For instance, Hopedale and Rigolet Inuit Community Governments in Newfoundland began the path toward food security with a community-led food assessment (CLFA), which involved all members of the community in examining issues affecting access to food and developing solutions to overcome challenges in a locally appropriate manner (Food First Newfoundland, n.d.). Subsequently, both Hopedale and Rigolet communities decided to establish community gardens and also join a Good Food Box program run by support organization Food First Newfoundland, which allows them to order food in bulk and thereby share the cost of shipping while choosing for themselves the types of foods that are ordered. These projects were implemented during a time when the only local store was selling overpriced (e.g., CA $\$ 70$ per turkey), low-grade, and often freezer-burned meats, 
and a ban on hunting caribou had come into effect in Rigolet (Food First Newfoundland, n.d.). Following its CLFA, the Hopedale community also decided to expand and enhance its community freezer program, which funded local hunters to provide meat for low-income families and for elders who have no family to hunt for them. These residents are provided with one piece of frozen meat per month, while supplies last (Food First Newfoundland, n.d.). Overall, grounded in an understanding of local food-related issues, the solutions put forth by communities in Hopedale and Rigolet were guided by a vision that is rooted in an Indigenous food sovereignty approach that has led to greater food security. As a result, the communities themselves determined the way in which they wanted to further the five As of food security.

\section{Conclusion}

Place matters. In particular, place shapes our lives because of its intimate interplay with food and food practices (Fitzpatrick \& Willis, 2015). Its impact can be dramatic, whether in urban slums, rural outbacks, world-class cities, or Indigenous communities, but it is not all predetermined. Placebased limits can be turned to advantage, especially for those who 'know their place.'

In spite of centuries of dis-placement and exclusion, Indigenous people have maintained their relationship to place and thus can offer an unparalleled experience of place-based food systems. In this paper, we presented an overview of placebased initiatives that are having a demonstrably positive impact on alternative food procurement in Indigenous communities. We provided context for these initiatives, mapped them, highlighted the trends among them, and discussed how they help to overcome the colonially structured food deserts that characterize the unjust nutrition transition and to support the just transition via the social economy to a place-based food system, anchored in Indigenous food sovereignty and food security.

Such initiatives have much to teach us when developing place-based food systems if we want them to reach their potential of not only re-valuing the local, but also fostering socio-ecological sustainability (Klassen \& Wittman, 2017). The lethal legacy of colonialism and exploitation in Indigenous communities in Canada must be exposed and ultimately undone, as has been demanded by the Truth and Reconciliation Commission (TRC, 2015). By turning to the communities to develop both culturally appropriate and economically linked alternative food procurement initiatives through organizational forms they choose, such as the social economy, this part of the lethal legacy can be slowly undone, and the solutions they develop can illuminate a just transition to a place-based food system for all.

\section{References}

Amin, A., Cameron, A., \& Hudson, R. (2002). Placing the social economy. New York: Routledge. https://doi.org/10.4324/9780203166123

Arctic Co-operatives Limited. (2007). Retail services. Retrieved from http://www.arcticco-op.com/services-retail-services.htm

Burnett, K., Skinner, K., Hay, T., LeBlanc, J., \& Chambers, L. (2017). Retail food environments, shopping experiences, First Nations and the provincial Norths. Health Promotion and Chronic Disease Prevention in Canada: Research, Policy and Practice, 37(10), 333-341. https://doi.org/10.24095/hpcdp.37.10.03

Centre for Studies in Food Security, Ryerson University. (2018). The five A's of food security. Retrieved from https://www.ryerson.ca/foodsecurity/

Climate Justice Alliance (CJA). (n.d.). Just transition principles. Retrieved from https://climatejusticealliance.org/wp-content/uploads/2018/06/CJA Just'Transition Principles final hi-rez.pdf

Cook, S., Smith, K., \& Utting, P. (2012). Green economy or green society? Contestation and policies for a fair transition (UNRISD Occasional Paper, No. 10). Geneva: United Nations Research Institute for Social Development (UNRISD).

Corntassel, J. (2012). Re-envisioning resurgence: Indigenous pathways to decolonization and sustainable selfdetermination. Decolonization Indigeneity Education and Society, 1, 86-101. 
Daschuk, J. (2015, June 4). Food and health on the western reserves: The deep roots of Indigenous food insecurity. Keynote address at the annual meeting of the Canadian Association for Food Studies, Congress of the Humanities and Social Sciences, Ottawa.

Fitzpatrick, K. M., \& Willis, D. (2015). A place-based perspective of food in society. New York: Palgrave Macmillan. https://doi.org/10.1057/9781137408372

Food First Newfoundland. (n.d.). Nikigijavut Nunatsiavutinni - Our Food NL: Nunatsiavut. Retrieved from http://www.foodfirstnl.ca/our-food-nl-nunatsiavut

Food Matters Manitoba. (2011). What's happening in Fox Lake? Retrieved from http://www.foodmattersmanitoba.ca/2011/05/whats-happening-fox-lake/

Gilbert, J. L., Schindel, A. E., \& Robert, S. A. (2018). Just transitions in a public school food system: The case of Buffalo, New York. Journal of Agriculture, Food Systems, and Community Development, 8(Suppl. 2), 95-113. https://doi.org/10.5304/jafscd.2018.08B.011

Global Greens. (2001). Charter of the Global Greens. Retrieved from https://www.globalgreens.org/global-greens-charterenglish

Goodman, D., Dupuis, M. E., \& Goodman, M. K. (2014). Alternative food networks: Knowledge, practice, and politics. New York: Routledge.

Heffron, R. J., \& McCauley, D. (2018). What is the 'just transition'? Geoforum, 88, 74-77. https://doi.org/10.1016/j.geoforum.2017.11.016

Hui, A. (2016, September 12; updated 2018, May 17). Indigenous people in Northern Ontario spend more than half of income on food: Report. The Globe and Mail. Retrieved from https://www.theglobeandmail.com/news/national/indigenous-people-in-northern-ontario-spend-more-than-halfof-income-on-food-report/article31822107/

Klassen, S. E., \& Wittman, H. (2017). Place-based food systems: "Re-valuing local" and fostering socio-ecological sustainability. In J. Duncan \& M. Bailey (Eds.), Sustainable food futures: Multidisciplinary solutions (pp. 46-60). New York: Routledge. https://doi.org/10.4324/9781315463131-4

Koç, M., Sumner, J., \& Winson, A. (2012). Critical perspectives in food studies (1 ${ }^{\text {st }}$ Edition). Toronto: Oxford University Press.

Koç, M., Sumner, J., \& Winson, A. (2017). Critical perspectives in food studies (2 ${ }^{\text {nd }}$ Edition). Toronto: Oxford University Press.

Kuhnlein, H. V., \& Receveur, O. (1996). Dietary change and traditional food systems of Indigenous peoples. Annual Review of Nutrition, 16, 417-442. https://doi.org/10.1146/annurev.nu.16.070196.002221

Martin, D. (2012). Nutrition transition and the public-health crisis: Aboriginal perspectives on food and eating. In M. Koç, J. Sumner, \& A. Winson (Eds.), Critical perspectives in food studies, $1^{\text {st }}$ Edition (pp. 208-222). Toronto: Oxford University Press.

Martin, D., \& Amos, M. (2017). What constitutes good food? Toward a critical Indigenous perspective on food and health. In M. Koç, J. Sumner, \& A. Winson (Eds.), Critical perspectives in food studies, $2^{\text {nd }}$ Edition (pp. 205-220). Toronto: Oxford University Press.

McMichael, P. (2010). Food sovereignty in movement: Addressing the triple crisis. In H. Wittman, A. A. Desmarais, \& N. Wiebe (Eds.), Food sovereignty: Reconnecting food, nature and community (pp. 168-185). Halifax, Nova Scotia: Fernwood.

McMurtry, J. J. (Ed.). (2010). Living economics: Canadian perspectives on the social economy, co-operatives, and community economic development. Toronto: Edmond Montgomery.

Mook, L., Quarter, J., \& Ryan, S. (Eds.). (2010). Researching the social economy. Toronto: University of Toronto Press. https://doi.org/10.3138/9781442660281

Morrison, D. (2011). Indigenous food sovereignty: A model for social learning. In H. Wittman, A. A. Desmarais, \& N. Wiebe (Eds.), Food sovereignty in Canada: Creating just and sustainable food systems (pp. 97-113). Halifax, Nova Scotia: Fernwood.

Newell, P., \& Mulvaney, D. (2013). The political economy of the 'just transition.' The Geographical Journal, 179(2), 132140. https://doi.org/10.1111/geoj.12008 
Northern Manitoba Food, Culture, and Community Collaborative (NMFCCC). (2016). Itbinto Mechisowin Program. Retrieved from http://www.nmfccc.ca/uploads/4/4/1/7/44170639/nmfccc 2016communitystories southindianlake print hr.pdf

NMFCCC. (2017). Community stories 2017. Retrieved from http://www.nmfccc.ca/community-stories.html

Patel, R. (2010). What does food sovereignty look like? In H. Wittman, A. A. Desmarais, \& N. Wiebe (Eds.), Food sovereignty: Reconnecting food, nature and community (pp. 186-196). Halifax, Nova Scotia: Fernwood.

Pollan, M. (2008). In defense of food: An eater's manifesto. New York: Penguin.

Popkin, B. (2003). The nutrition transition in the developing world. Development Policy Review, 21(5-6), 581-597. https://doi.org/10.1111/j.1467-8659.2003.00225.x

Pulido, L. (2000). Environmental justice. In R. J. Johnston, D. Gregory, G. Pratt, \& M. Watts (Eds.), The Dictionary of Human Geography (4th Edition) (pp. 218-220). Malden, Massachusetts: Blackwood.

Samson, C. (2016). Reversing the nutrition transition among native North Americans. Institute on Science for Global Policy. Retrieved from http://scienceforglobalpolicy.org/wp-content/uploads/5718fdf039e4aSamson\%20policy\%20position\%20paper.pdf

Shragge, E., \& Fontan, J.-M. (2000). Social economy: International debates and perspectives. Montreal: Black Rose Books.

Sumner, J. (2005). Social justice. In L. English (Ed.), The Encyclopedia of Adult Education (pp. 580-584). New York: Palgrave Macmillan.

Sumner, J. (2017). Conceptualizing sustainable food systems. In M. Koç, J. Sumner, \& A. Winson (Eds.), Critical perspectives in food studies, $2^{\text {nd }}$ Edition (pp. 320-331). Toronto: Oxford University Press.

Swilling, M., \& Annecke, E. (2012). Just transitions: Explorations of sustainability in an unfair world. Tokyo: United Nations University Press.

Thompson, S., Kamal, A. G., Alam, M. A., \& Wiebe, J. (2012). Community development to feed the family in northern Manitoba communities: Evaluating food activities based on their food sovereignty, food security, and sustainable livelihood outcomes. Canadian Journal of Nonprofit and Social Economy Research, 3(2), 43-66. https://doi.org/10.22230/cjnser.2012v3n2a121

Truth and Reconciliation Commission of Canada (TRC). (2015). Final report of the Truth and Reconciliation Commission of Canada. Retrieved from http:/

United Nations Research Institute for Social Development (UNRISD). (2018). Mapping just transition(s) to a low-carbon world. A report of the Just Transition Research Collaborative, United Nations Research Institute for Social Development. Retrieved from http://www.unrisd.org/80256B3C005BCCF9/(httpPublications)/9B3F4F10301092C7C12583530035C2A5?Open Document

Winson, A. (2017). Spatial colonization of food environments by pseudo food companies: Precursors of a health crisis. In M. Koç, J. Sumner, \& A. Winson (Eds.), Critical perspectives in food studies, $2^{\text {nd }}$ Edition (pp. 185-204). Toronto: Oxford University Press.

Wuttunee, W. (2010). Aboriginal perspectives on the social economy. In J. J. McMurtry (Ed.), Living economics: Canadian perspectives on the social economy, co-operatives, and community economic development (pp. 179-215). Toronto: Edmond Montgomery.

Yukon Hospitals. (2018). First Nations Health Cultural Programs. Retrieved from https://yukonhospitals.ca/whitehorsegeneral-hospital/programs-and-services/first-nations-health-cultural-programs 